\title{
The LifeLines Cohort Study: a resource providing new opportunities for environmental epidemiology
}

\author{
Wilma L. Zijlema ${ }^{1 *}$, Nynke Smidt ${ }^{1}$, Bart Klijs ${ }^{1}$, David W. Morley², John Gulliver ${ }^{2}$, Kees de Hoogh ${ }^{2,3,4}$, \\ Salome Scholtens ${ }^{5}$, Judith G. M. Rosmalen ${ }^{6}$ and Ronald P. Stolk ${ }^{1,5}$
}

\begin{abstract}
Background: Lifelines is a prospective population-based cohort study investigating the biological, behavioral and environmental determinants of healthy ageing among 167,729 participants from the North East region of the Netherlands. The collection and geocoding of (history of) home and work addresses allows linkage of individual-level health data to detailed exposure data. We describe the reasons for choosing particular assessments of environmental exposures in LifeLines and consider the implications for future investigations.

Methods: Exposure to ambient air pollution and road traffic noise was estimated using harmonized models. Data on noise annoyance, perceived exposure to electromagnetic fields, perceived living environment, and neighborhood characteristics were collected with questionnaires. A comprehensive medical assessment and questionnaires were completed in order to assess determinants of health and well-being. Blood and urine samples were collected from all participants and genome wide association data are available for a subsample of 15,638 participants.

Results: Mean age was 45 years (standard deviation (SD) 13 years), and $59 \%$ were female. Median levels of $\mathrm{NO}_{2}$ and $\mathrm{PM}_{10}$ were 15.7 (interquartile range (IQR) 4.9) $\mathrm{\mu g} / \mathrm{m}^{3}$ and 24.0 (IQR 0.6$) \mu \mathrm{g} / \mathrm{m}^{3}$ respectively. Median levels of daytime road traffic noise were 54.0 (IQR 4.2) dB(A).

Conclusions: The combination of harmonized environmental exposures and extensive assessment of health outcomes in LifeLines offers great opportunities for environmental epidemiology. LifeLines aims to be a resource for the international scientific community.
\end{abstract}

Keywords: Prospective cohort study, Environmental exposures, Harmonization, Chronic disease

\section{Background}

Environmental epidemiology has contributed to public health by focusing on the reduction of harmful exposures from the environment. Smoke-free legislation [1], control of particulate air pollution [2], and the introduction of proper sanitation [3] are examples of policies that resulted in substantial benefits for public health. Current efforts in the Netherlands to reduce exposure to air pollution include the introduction of "environmental zones" where only clean vehicles are allowed, the mandatory

\footnotetext{
* Correspondence: wzijlema@creal.cat

${ }^{1}$ Department of Epidemiology, University Medical Center Groningen, HPC CC72, University of Groningen, PO Box 30.0019700 RB Groningen, The Netherlands

Full list of author information is available at the end of the article
}

use of particulate filters in vehicles, and the introduction of clean public transport. Although large efforts have been made, more is to gain in environmental epidemiology, both in terms of public health policy and research. Prevention of harmful environmental exposures is important because many of these exposures are often involuntary and outside the immediate control of the individual, and many individuals may be affected by the same pollution source.

Studying health effects of environmental exposures can be challenging. Environmental exposures often occur in low concentrations and in complex mixtures. Most health outcomes of interest have many underlying risk factors whose effects may be much stronger than those of the environmental exposure. Risks associated with environmental exposures are generally small [4], making them difficult 
to detect. Although effect sizes are small, impacts on health are still substantial because of the large number of exposed persons. Population based cohort studies with large sample sizes are needed to investigate the complex interaction between genetic, behavioral, and environmental factors in the development of multifactorial chronic diseases. Collaboration between cohort studies could help understand environmental causes of disease, and the advantages of such an approach are widespread. Such collaboration will lead to large sample sizes and wide exposure ranges. Furthermore, results can be compared across regions, in which not only the exposures, but also genetic, social and cultural factors vary, making the generalizability of study results larger. Generalizing study results across large regions in Europe is important for establishing European exposure norms and guidelines. The harmonization and standardization of population studies will enable the assembling of data in valid and effective ways. To this end, LifeLines aims to implement standardized and harmonized data collection methods.

LifeLines is one of eight studies participating in the BioSHaRE (Biobank Standardisation and Harmonisation for Research Excellence in the European Union, www.bioshare.eu) project. Within the framework of this European harmonization initiative, tools were developed for data harmonization, database integration and federated data analyses [5]. Standardized and validated methods were used wherever possible, and a part of the dataset (e.g., educational level, alcohol and tobacco use) has been retrospectively harmonized with other European cohorts [6].

Our aim is to inform researchers on the choice of data collection methods and methodology of data on environmental exposures in LifeLines. Descriptive information of selected exposure and cohort data will be reported. By describing these features of LifeLines we aim to highlight methodological choices made in the context of large population based cohort studies exposed to multiple environmental stressors.

\section{Methods}

\section{Study design and participants}

LifeLines is a multi-disciplinary prospective population based cohort study examining the health and healthrelated behaviors of persons living in the North East region of the Netherlands. The cohort was established to facilitate research on complex interactions between environmental, phenotypic and genetic factors in the development of chronic diseases [7, 8]. Recruitment of study participants took place between 2006 and 2013. In the Netherlands, all inhabitants are registered with a general practitioner. A large number of general practitioners from the Northern provinces of the Netherlands participated in the recruitment and invited all their patients between ages 25 and
50 years. Individuals who agreed to participate were asked to indicate whether their family members would also be willing to participate. In addition, individuals could also register themselves via the LifeLines website. The sample was recruited from the three Northern provinces of the Netherlands, but this was not a requirement for inclusion of family members [8]. Characteristics of adult LifeLines participants are broadly representative for the adult population of the North of the Netherlands [9].

Baseline data were collected from 167,729 participants, aged 6 months to 93 years. Follow-up is planned for at least 30 years, with questionnaires administered every 1.5 years, and a renewed physical examination scheduled every five years. Participants visited one of the LifeLines research sites for a physical examination, including spirometry, electrocardiogram (ECG), blood pressure measurements, anthropometry, cognition tests, and a psychiatric interview. Fasting blood and 24-h urine samples were collected from all participants, and genome wide association data are currently available for a subsample of 15,638 participants. An extensive baseline questionnaire was completed at home, including questions on history of illness, health related quality of life, lifestyle, socioeconomic status, psychosocial stress, work (profession, working hours), psychosocial characteristics, and medication use. Linkage will be established with records from general practitioners and health registries. A comprehensive and detailed overview of the available data is presented in the online LifeLines Data Catalogue (www.lifelines.net).

\section{Geocoding}

All participants' home addresses were geocoded. In addition to the most recent home address, address history is available from the Municipal Personal Record Database. This governmental registry contains personal data of all individuals who live or have lived in the Netherlands. Data on address history provide insights in residential mobility and length of exposure to different environments, and allows assessment of long-term exposures relevant for life course epidemiology. Work addresses were also collected and will be geocoded as well, allowing for outdoor exposure estimation of air pollution and noise at both home and work location. Most studies estimate exposure to road traffic noise and air pollution at the home addresses of participants (e.g., $[10,11])$, assuming this to be a good indicator of personal exposure. Individuals spend a large amount of their time at the work address, and combining exposures from both locations will result in better estimations of exposure [12]. A detailed description of the environmental exposures assessed in LifeLines is described below, and is summarized in Table 1. 
Table 1 Overview of environmental exposures in the LifeLines Cohort Study

\begin{tabular}{|c|c|}
\hline Ambient air pollution & \\
\hline \multicolumn{2}{|l|}{ ESCAPE models } \\
\hline $\mathrm{NO}_{2}$ & Nitrogen dioxide \\
\hline $\mathrm{NO}_{2}$ background & Background level of nitrogen dioxide \\
\hline $\mathrm{PM}_{2.5}$ & Particulate matter with diameter $\leq 2.5 \mu \mathrm{m}$ \\
\hline $\mathrm{PM}_{2.5}$ absorbance & $\begin{array}{l}\text { Reflectance on } \mathrm{PM}_{2.5} \text { filters, i.e., marker } \\
\text { of black carbon }\end{array}$ \\
\hline $\mathrm{PM}_{10}$ & Particulate matter with diameter $\leq 10 \mu \mathrm{m}$ \\
\hline \multicolumn{2}{|l|}{ EU-wide models } \\
\hline $\mathrm{NO}_{2}$ & Nitrogen dioxide \\
\hline $\mathrm{PM}_{10}$ & Particulate matter with diameter $\leq 10 \mu \mathrm{m}$ \\
\hline \multicolumn{2}{|l|}{$\begin{array}{l}\text { Road traffic noise } \\
\text { (CNOSSOS-EU model) }\end{array}$} \\
\hline $\mathrm{L}_{\text {day }}$ & $\begin{array}{l}\text { A-weighted equivalent noise level over } \\
\text { the } 12 \text {-hour day time period from } 07.00 \\
\text { to } 19.00 \text { hour }\end{array}$ \\
\hline$L_{\text {evening }}$ & $\begin{array}{l}\text { A-weighted equivalent noise level over } \\
\text { the } 4 \text {-hour evening time period from } \\
19.00 \text { to } 23.00 \text { hours }\end{array}$ \\
\hline$L_{\text {night }}$ & $\begin{array}{l}\text { A-weighted equivalent noise level over } \\
\text { the } 8 \text {-hour night time period from } \\
23.00 \text { to } 07.00 \text { hours }\end{array}$ \\
\hline$L_{\text {aeq16 }}$ & $\begin{array}{l}\text { A-weighted equivalent noise level over } \\
\text { the } 16 \text {-hour day and evening time } \\
\text { period from } 07.00 \text { to } 23.00 \text { hours }\end{array}$ \\
\hline$L_{\text {den }}$ & $\begin{array}{l}\text { A-weighted equivalent noise level for } \\
\text { the day-evening-night time period of } \\
24 \text { hours, with a } 10 \mathrm{~dB} \text { penalty added } \\
\text { to the levels between } 23.00-07.00 \text { hours } \\
\text { and a } 5 \mathrm{~dB} \text { added to the levels between } \\
19.00-23.00 \text { hours to reflect extra noise } \\
\text { sensitivity during night and evening }\end{array}$ \\
\hline$L_{\text {aeq }} 0-23$ hours & Hourly noise estimates \\
\hline
\end{tabular}

Questionnaire data

Noise annoyance

Perceived exposures to power lines, mobile phone masts

Mobile phone use

Exposure to secondhand smoke

Perceived living environment

Database linkage

Neighborhood characteristics (Statistics Netherlands)

LISA employment register

Neighborhood level demographic and socioeconomic figures

Location, type of establishment, number of employees

ESCAPE European Study of Cohorts for Air Pollution Effects, EU-wide Europeanwide, CNOSSOS-EU Common Noise Assessment Methods in Europe

\section{Ambient air pollution}

Exposure to air pollution has been related to various health outcomes, including respiratory diseases [13] and cardiovascular disease [14]. In LifeLines, exposure to ambient air pollution was estimated using land use regression (LUR) models developed for the European Study of Cohorts for Air Pollution Effects (ESCAPE) $[15,16]$ and using European wide LUR models enhanced with satellite derived air pollution estimates [17]. It was chosen to implement these air pollution models in LifeLines because both models are advantageous regarding comparability across studies in other European regions.

Within the ESCAPE project, LUR models for various European study areas were developed using a standardized approach. ESCAPE LUR models were developed for $\mathrm{NO}_{2}$ (nitrogen dioxide), $\mathrm{NO}_{2}$ background, $\mathrm{PM}_{2.5}$ (particulate matter with a diameter $\leq 2.5 \mu \mathrm{m}$ ), $\mathrm{PM}_{2.5}$ absorbance (reflectance on $\mathrm{PM}_{2.5}$ filters, i.e., a marker of black carbon), and $\mathrm{PM}_{10}$ (particulate matter with a diameter $\leq 10 \mu \mathrm{m}$ ), and were based on annual average concentrations from an intensive monitoring campaign and GIS (geographic information system) derived predictor variables (e.g., distance to the nearest major road, traffic intensity, built-up land, population density, altitude). LUR models were developed using measurements carried out in 2009-2010 and predictor variable data for the same years. Model performance was evaluated by leave-one-out cross validation. The adjusted explained variability in measured concentrations $\left(R^{2}\right)$ was 0.85 for $\mathrm{NO}_{2}, 0.83$ for $\mathrm{NO}_{2}$ background, 0.66 for $\mathrm{PM}_{10}$, 0.64 for $\mathrm{PM}_{2.5}$, and 0.91 for $\mathrm{PM}_{2.5}$ absorbance $[15,16]$.

In addition, exposure to ambient $\mathrm{PM}_{10}$ and $\mathrm{NO}_{2}$ is available from European(EU)-wide models. These EUwide models incorporate GIS-derived land use, road network, and topographic data, as well as satellitederived estimates of ground level concentrations for $\mathrm{PM}_{2.5}$ (as an indicator of $\mathrm{PM}_{10}$ ) and $\mathrm{NO}_{2}$. Model development follows the ESCAPE procedure to construct the multiple linear regression equations, and are applicable for years 2005, $2006\left(\mathrm{NO}_{2}\right)$ and $2007\left(\mathrm{NO}_{2}\right.$ and $\left.\mathrm{PM}_{10}\right)$. Models were evaluated against measured $\mathrm{PM}_{10}$ and $\mathrm{NO}_{2}$ concentrations at an independent subset of sites reserved for this purpose. The adjusted explained variability in measured concentrations $\left(R^{2}\right)$ was $0.48-0.58$ for $\mathrm{NO}_{2}$, and $0.22-0.50$ for $\mathrm{PM}_{10}$ [17].

The main difference between the ESCAPE and EUwide models is that the ESCAPE models are region specific, while EU-wide models are developed for a much larger area. ESCAPE models are developed for 20 (PM) to $36\left(\mathrm{NO}_{2}\right)$ European regions and EU-wide models for 17 countries in Western Europe. In addition, monitoring data used in ESCAPE models originated from a monitoring campaign specifically conducted for the ESCAPEproject with monitoring sites selected for this purpose, whereas monitoring data for the EU-wide models were obtained from regulatory monitoring networks. A study including Lifelines and other cohorts falling in ESCAPE study areas (e.g., the British cohort EPIC-Oxford, also 
involved in BioSHaRE) should use air pollution exposures estimates from the relevant ESCAPE models. However, the EU-wide model can also provide air pollution exposure estimates for areas falling outside the ESCAPE study areas, and will therefore allow research including Lifelines plus non-ESCAPE cohorts (e.g., the Norwegian cohort HUNT, also involved in BioSHaRE).

\section{Road traffic noise}

Environmental noise has been related to a variety of adverse outcomes, including hearing loss, annoyance, sleep disturbance, cognitive impairment, and cardiovascular disease [18]. In LifeLines, road traffic noise was estimated using an implementation of the Common Noise Assessment Methods in Europe (CNOSSOS-EU) noise modeling framework [19], which was developed as a common methodology for noise modeling across Europe. This noise model was preferred since it allows comparison of results from different countries. The CNOSSOS-EU noise model implemented within LifeLines uses lower resolution source data because the highest resolution input data at national or large regional level is either unavailable, expensive or would be too computationally intensive to process. The performance of CNOSSSOS-EU using the lower resolution inputs has been shown to be reasonable for application in epidemiological studies. The model's exposure ranking, i.e., prediction of noisier and quieter sites, was adequate (Spearman's rank $=0.75 ; \mathrm{p}<0.001$ ), but the predicted noise levels have relatively large errors (root mean square error $($ RMSE $)=4.46 \mathrm{~dB}(\mathrm{~A}))[20]$.

The CNOSSOS-EU framework contains empirically derived equations to determine the initial noise level based on traffic flow and sound attenuation (i.e., sound reduction or damping) based on known environmental factors and physical processes. To estimate source noise on road segments in the Netherlands, traffic information was obtained including hourly flow of passenger cars, heavy goods vehicles and their average speeds. As detailed land cover data were not available to allow positioning of the receptor at the most exposed façade, a coarser land cover data set was used to approximate urban fabric. The sound propagation model was based on the CORINE (Coordination of information on the environment) land cover dataset that has a European wide coverage accurate to $100 \mathrm{~m}$ for major land cover types [21]. In particular, the distinction between urban fabric and areas of vegetation was made. Traffic data originated from year 2009 and landcover data from 2006. Full details of this approach are described by Morley and colleagues (2015) who show that lower resolution data may be used within the CNOSSOS-EU noise model to obtain representative exposure estimates [20].

\section{Perceived exposures}

Besides the actual exposure to environmental factors, perceived exposure and concerns about the health risks associated with the exposure might influence health outcomes [22]. When studying particular exposures, for example electromagnetic fields, the public's perception of the health risks is as relevant to health as the exposure itself. Moreover, sometimes perceived exposures have stronger associations with diminished health than the actual exposures [23]. Noise annoyance from eight different sources was measured using a standardized selfreport questionnaire. The sources of noise annoyance include for example air, road and rail traffic. This questionnaire originates from the International Organization for Standardization (ISO) guideline, which provides specifications for socio-acoustic surveys and social surveys that include questions on noise effects [24]. Similar noise annoyance questions were used in the HYENA study on HYpertension and Exposure to Noise near Airports [25]. Perceived exposure to electromagnetic fields is measured using a questionnaire on perceived exposure to power lines and mobile phone masts. Participants were asked to what extent they think they are exposed to radiation from power lines and mobile phone masts, and whether they perceive this as bad for their health (adapted from [26]). In addition, a number of questions on the use of mobile phones (e.g., average time per week using mobile phone; on which side of the head) were included. These questions were adapted from the UKBiobank questionnaire [27], which is one of the cohorts involved in the BioSHaRE project. Exposure to second-hand smoke is assessed with questions about the duration and place (household, workplace) of exposure, and originate from the European Community Respiratory Health Survey [28].

In addition to work addresses, information was collected on working hours and type of profession, which may be relevant for occupational exposure studies. In the next follow-up questionnaire, LifeLines will measure how participants perceive their living environment. The questionnaire comprises of nine items investigating characteristics of the physical and social living environment as perceived by the respondent (e.g., neighborhood satisfaction, social interaction with neighbors), and was based on the 2010 health survey of the Dutch Community Health Services (Dutch name: GGD Gezondheidsenquête 2010) [29] and the 2006 WoON questionnaire (Dutch name: WoonOnderzoek Nederland) [30].

\section{Neighborhood characteristics}

Various neighborhood characteristics have been associated with health, ranging from cardiometabolic risk factors [31] to life expectancy [32]. Data on neighborhood characteristics from Statistics Netherlands are available for linkage to the LifeLines database. Statistics Netherlands publishes 
demographic and socioeconomic figures for municipalities, districts and neighborhoods [33]. These figures cover various themes, for example housing, education, income, and land use. Such information enables to investigate the impact of neighborhood conditions on health.

Furthermore, the LISA employment register (www.lisa.nl) is linked to the LifeLines database. This register contains nationwide information on locations (geocoded at the address level) of establishments where paid work is done. The database also contains information about the type of establishment (i.e., restaurants, hospitals, shops) and the number of employees. Using the LISA employment register, it is possible to investigate the density and distance to specific facilities in relation to various health outcomes.

\section{Data access and linkage}

LifeLines has adopted an open protocol, meaning that within the standing infrastructure additional data and biomaterial collection, and linkage with other (environmental) data sources can be implemented, for example for the purpose of environmental biomonitoring of exposure and response. One example is LifeLines DEEP, an add-on study where in a subsample of participants additional biological samples (feces, exhaled air) were collected, additional blood analyses were undertaken, and additional questionnaires were filled out [34]. Other exposures types, such as domestic radon, electromagnetic fields, harmful chemicals (e.g., pesticides) are of interest for research in LifeLines, and proposals for additional environmental exposures assessments relevant for healthy ageing are warmly welcomed. Furthermore, biological samples are stored for future analyses, enabling for example measurement of exposure biomarkers. Data and biomaterials are provided on a fee-for-service basis and may be used for scientific research only. Public and private researchers, from inside and outside the Netherlands are invited to submit a research proposal to the LifeLines Research Office (LLscience@umcg.nl). Quality control of data is done by trained medical students and data managers, using Standard Operating Procedures (SOPs). Data is released within a remote system (LifeLines workspace) running on a high performance computer cluster, which ensures data quality and security. The LifeLines research website (www.lifelines.net) provides the details of the application process, the data collection, and an overview of publications with LifeLines data.

Table 2 Sample characteristics by sex of the LifeLines Cohort Study

\begin{tabular}{|c|c|c|c|}
\hline & Women & Men & Total \\
\hline $\mathrm{N}^{\mathrm{a}}(\%)$ & $56053(58.7)$ & $39379(41.3)$ & 95432 \\
\hline Age (years) & $44.9(12.6)$ & $45.7(12.7)$ & $45.2(12.6)$ \\
\hline \multicolumn{4}{|l|}{ Education (\%) } \\
\hline No or primary & 3.2 & 3.0 & 3.1 \\
\hline Lower or preparatory vocational & 12.4 & 16.2 & 14.0 \\
\hline Lower general secondary & 16.0 & 11.7 & 14.2 \\
\hline Intermediate vocational or apprenticeship & 30.6 & 31.0 & 30.8 \\
\hline Higher general secondary or pre-university secondary & 9.9 & 7.0 & 8.7 \\
\hline Higher vocational or university & 28.1 & 31.0 & 29.3 \\
\hline Current smokers (\%) & 20.4 & 23.8 & 21.8 \\
\hline $\mathrm{BMI}\left(\mathrm{kg} / \mathrm{m}^{2}\right)$ & $25.9(4.7)$ & $26.4(3.7)$ & $26.1(4.3)$ \\
\hline $\mathrm{SBP}(\mathrm{mmHg})$ & $122.1(15.3)$ & $130.7(14.0)$ & $125.6(15.3)$ \\
\hline $\mathrm{DBP}(\mathrm{mmHg})$ & $71.8(8.7)$ & $76.6(9.3)$ & $73.8(9.3)$ \\
\hline $\mathrm{FVC}(\mathrm{L})$ & $3.9(0.6)$ & $5.4(0.9)$ & $4.5(1.1)$ \\
\hline FEV1 (L) & $3.0(0.6)$ & $4.1(0.8)$ & $3.5(0.8)$ \\
\hline \multicolumn{4}{|l|}{ Urbanity ${ }^{\mathrm{b}}(\%)$} \\
\hline Rural & 40.8 & 41.9 & 41.2 \\
\hline Semi-rural & 24.3 & 25.4 & 24.8 \\
\hline Intermediate urban-rural & 17.5 & 16.7 & 17.1 \\
\hline Semi-urban & 10.6 & 10.1 & 10.4 \\
\hline Urban & 6.8 & 6.0 & 6.5 \\
\hline
\end{tabular}

Means (SD) are presented for continuous variables, and percentages are presented for categorical variables

${ }^{a}$ Data are based on the first data release of $n=95,432$

${ }^{\mathrm{b}}$ Average number of addresses per $\mathrm{km}^{2}$ within a range of 1 kilometer, categorized into five levels ranging from rural $\left(<500\right.$ addresses per $\left.\mathrm{km}^{2}\right)$ to urban $(\geq 2500$ addresses per $\mathrm{km}^{2}$ )

Abbreviations: BMI body mass index, SBP systolic blood pressure, DBP diastolic blood pressure, FVC forced vital capacity, FEV1 forced expiratory volume in 1 second 


\section{Results}

The first data release of the baseline sample consisted of 95,432 participants, of which $58.7 \%$ were female. Mean age was 45.2 years (standard deviation (SD) 12.6 years), and men were more often current smokers than women (23.8 and $20.4 \%$, respectively). Overall, mean body mass index (BMI) was $26.1 \mathrm{~kg} / \mathrm{m}^{2}$ (SD $4.3 \mathrm{~kg} / \mathrm{m}^{2}$ ), and mean systolic blood pressure was $125.6 \mathrm{mmHg}$ (SD $15.3 \mathrm{mmHg}$ ). Forced vital capacity (FVC), a measure for lung function assessed with spirometry, was on average 4.5 (SD 1.1) liters. Most participants live in rural (i.e., $<500$ addresses per $\mathrm{km}^{2}$ ) neighborhoods (41.2 \%) (Table 2).
Most participants live in the three Northern provinces of the Netherlands, but part of the participants (approximately $3 \%$ ) live elsewhere in the country (Fig. 1). Median levels of $\mathrm{NO}_{2}$ were 15.7 (interquartile range (IQR) 4.9$) \mu \mathrm{g} / \mathrm{m}^{3}$ (ESCAPE) and 20.6 (IQR 7.9) $\mu \mathrm{g} / \mathrm{m}^{3}$ (EU-wide), and 24.0 (IQR $0.6) \mu \mathrm{g} / \mathrm{m}^{3}$ (ESCAPE) and 23.6 (IQR 2.4) $\mu \mathrm{g} / \mathrm{m}^{3}$ (EU-wide) for $\mathrm{PM}_{10}$ (Fig. 2). Correlation between ESCAPE-LUR modeled $\mathrm{NO}_{2}$ and satellite-enhanced LUR modeled $\mathrm{NO}_{2}$ was high (Spearman's rho $=0.86$ ), while correlation for $\mathrm{PM}_{10}$ from both models was moderate (Spearman's rho $=0.54$ ).

Median levels of road traffic noise were 54.0 (IQR 4.2) $\mathrm{dB}(\mathrm{A})$ (decibel (A)) for $\mathrm{L}_{\text {day }}$ (A-weighted equivalent noise

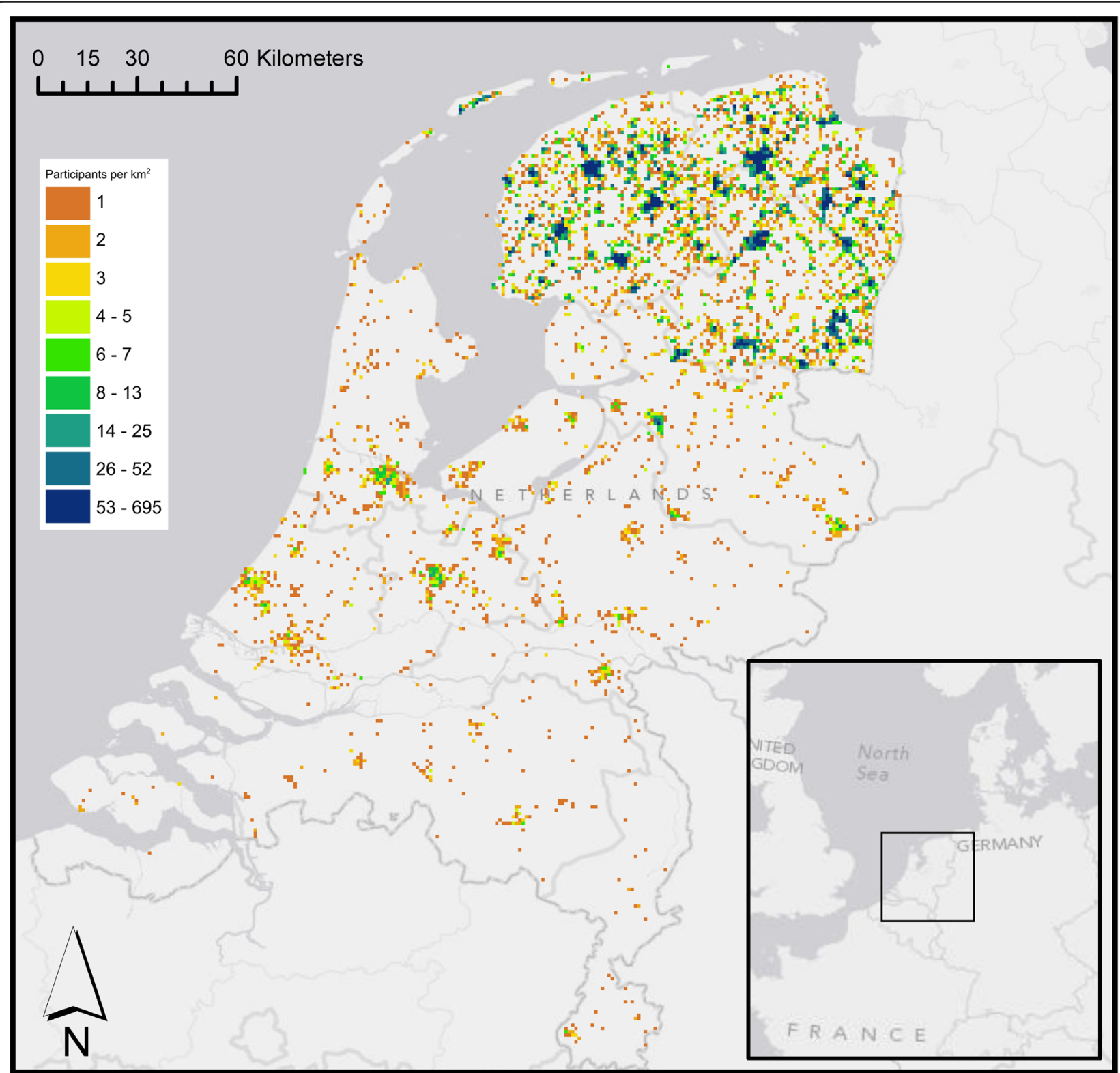

Fig. 1 LifeLines study area and number of participants per square kilometer. Participants were aggregated and plotted at the center of each 1 $\mathrm{km}$ grid cell 


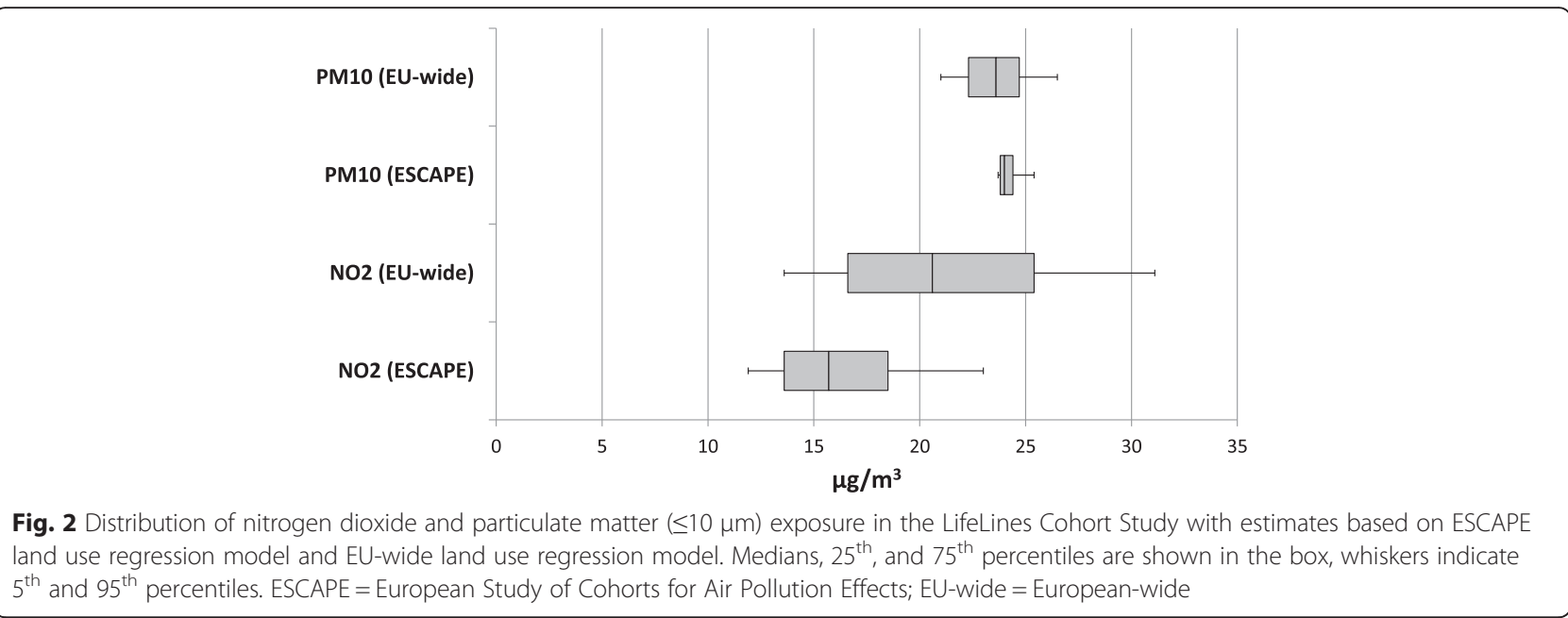

level over the 12-h day time period from 07.00 to $19.00 \mathrm{~h}$ ) and 45.1 (IQR 4.2) dB(A) for $\mathrm{L}_{\text {night }}$ (A-weighted equivalent noise level over the 8 -h night time period from 23.00 to $07.00 \mathrm{~h}$ ) (Fig. 3). LifeLines participants living in urban neighborhoods had highest exposure to air pollution $\left(\mathrm{NO}_{2}\right.$; Fig. 4) and 24-h road traffic noise $\left(\mathrm{L}_{\mathrm{den}}\right)$ (Fig. 5), compared to participants in neighborhoods of lower degree of urbanity. The correlation between (ESCAPE modeled) $\mathrm{NO}_{2}$ and urbanity was Spearman's rho: 0.88 $(\mathrm{p}<0.001)$ and Spearman's rho: $0.42(\mathrm{p}<0.001)$ for $\mathrm{L}_{\mathrm{den}}$ and urbanity.

\section{Discussion}

With 167,729 participants, LifeLines is one of the largest population based cohort studies of the world. A large amount of data is collected, biological samples are stored for future analyses (e.g., measurement of exposure biomarkers), and for a subsample of 15,638 participants genome wide genotype data are available. These numbers are large enough for studying effects of environmental exposures in vulnerable subgroups. This is important, because many factors (genetics, individual disease states, psychosocial stress, and socioeconomic status) have the potential to interact with environmental exposures [35]. The major strength of this study is the use of harmonized exposure models for ambient air pollution and for road traffic noise, and the use of validated questionnaires. Data harmonization facilitates comparability and combination with data from other cohorts and regions, which is beneficial for environmental epidemiology, where large sample sizes and broad exposure ranges are needed. Existing and future collaborations with other biobanks and international consortia hold the promise of answering complex questions in environmental epidemiology. Furthermore, the prospective nature of LifeLines allows research into long-term effects of environmental exposures. In addition, both objective (modeled) and subjective (questionnaire based)

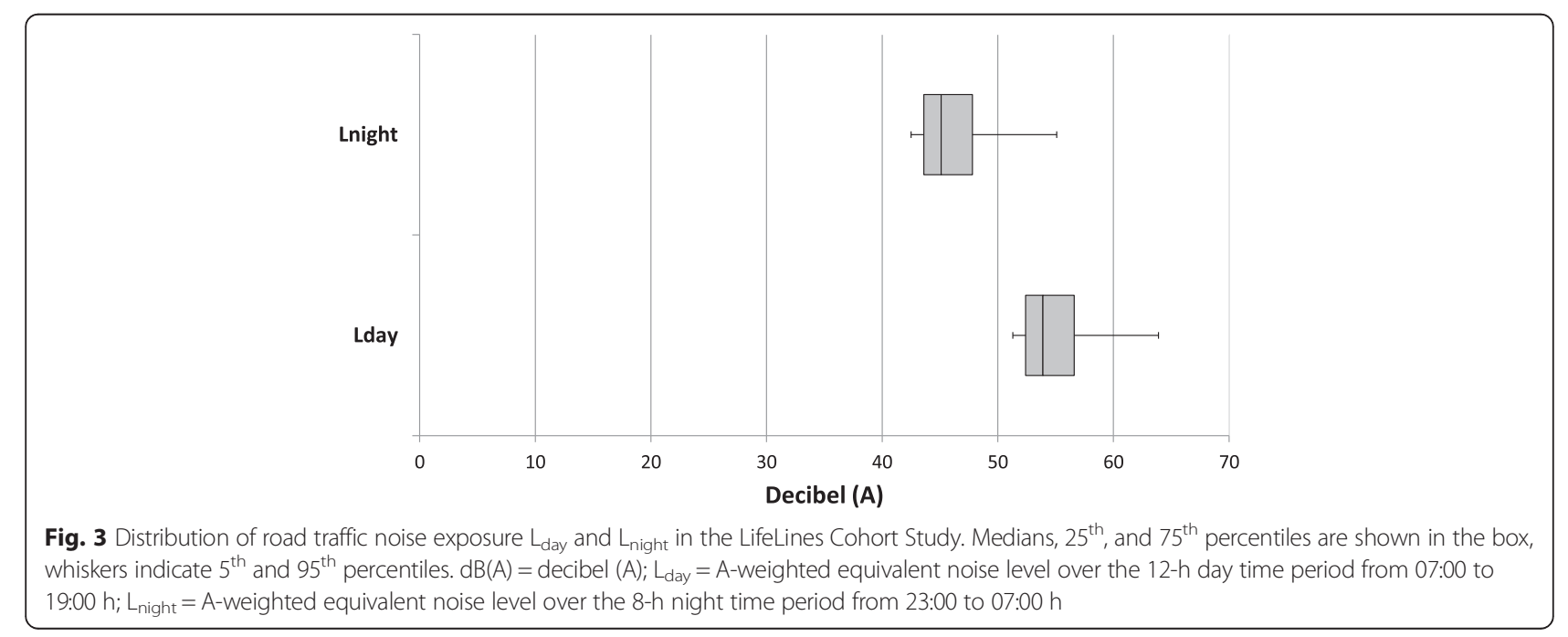




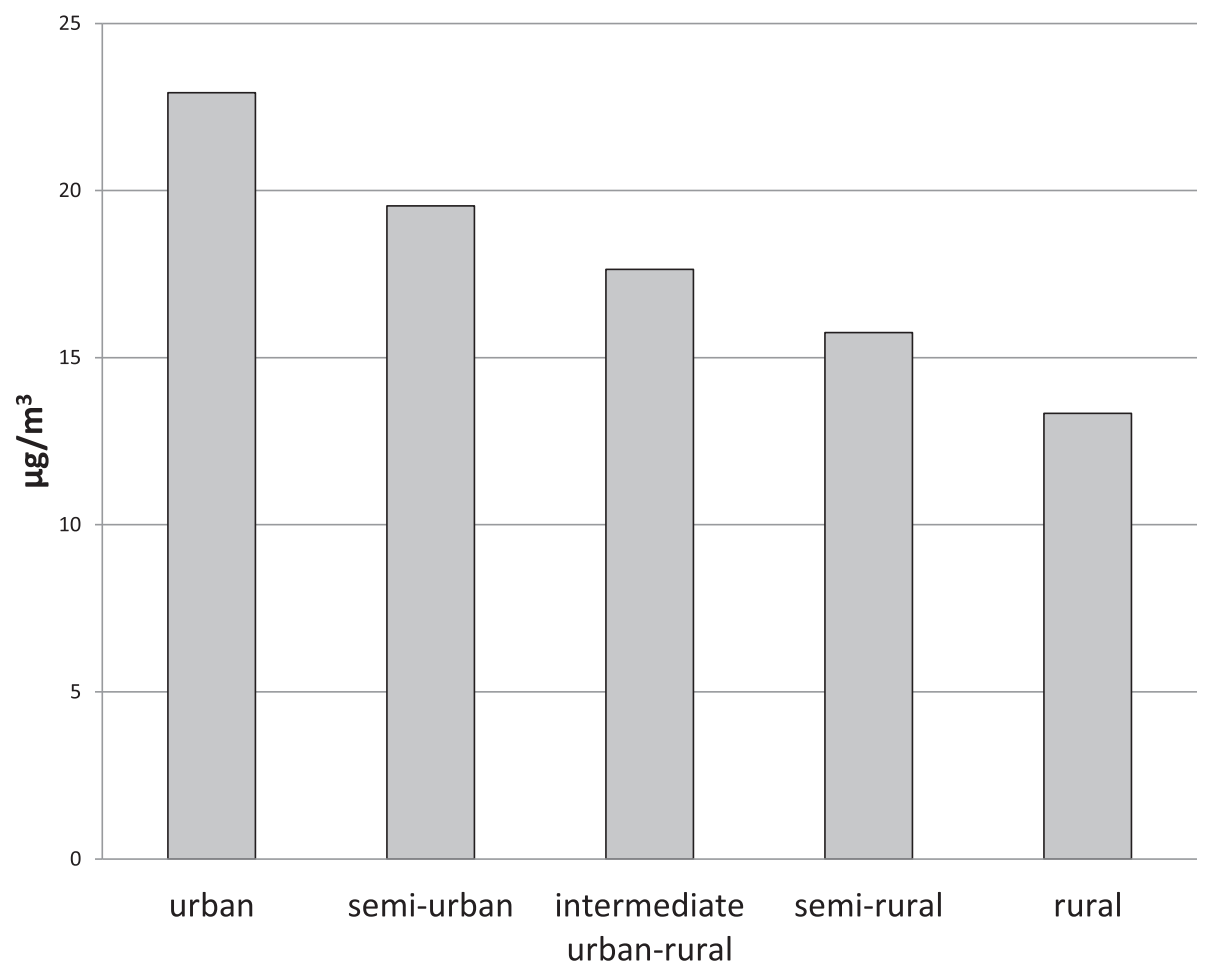

Fig. 4 Median exposure to ambient nitrogen dioxide $\left(\mathrm{NO}_{2}\right.$; based on ESCAPE model) according to degree of urbanity within the LifeLines Cohort Study

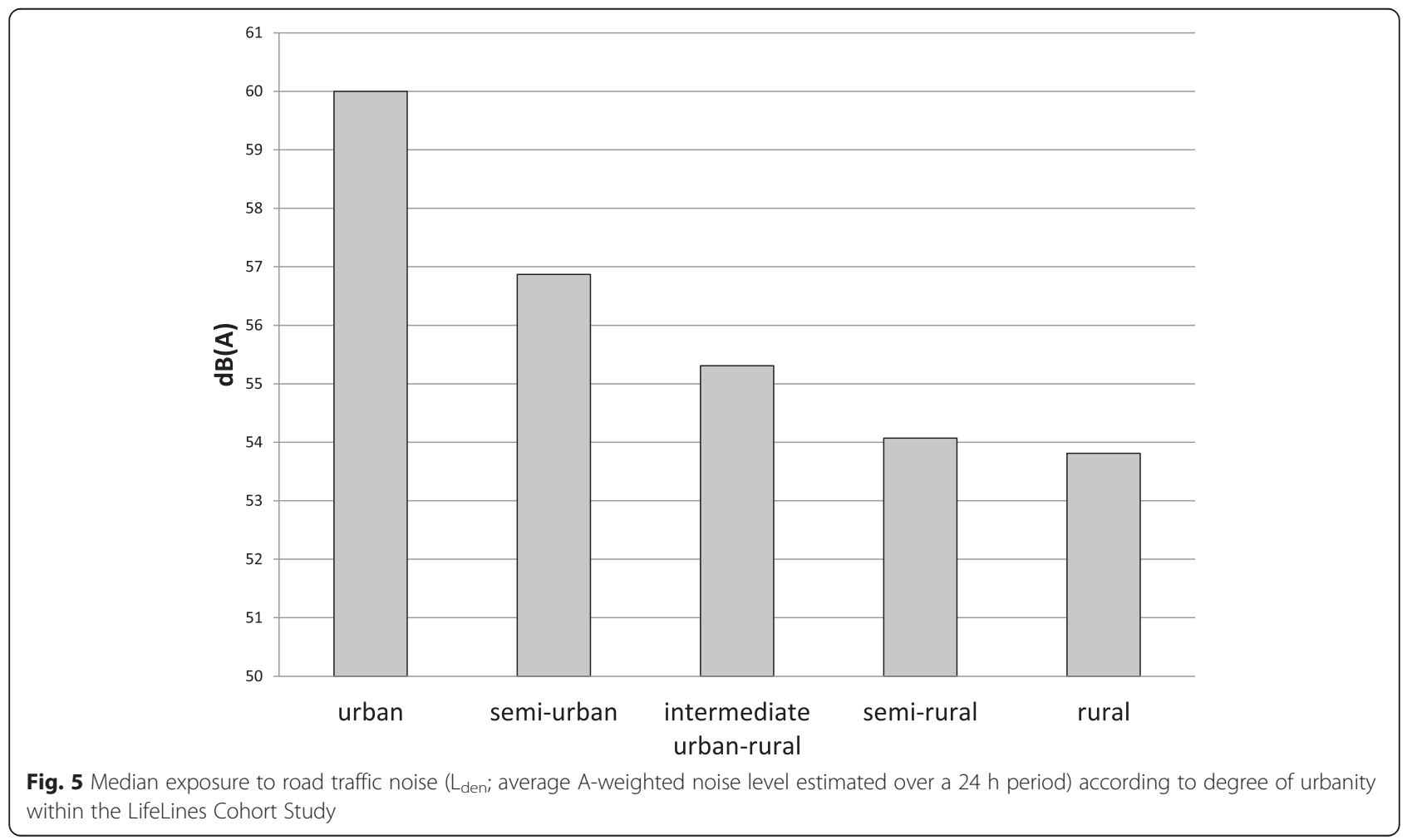


exposures were assessed. This enables studying effects of the exposure itself, and of perception of the exposure.

One limitation is that the results in this paper were based on the first 95,432 participants that were included in LifeLines. Geocoding and exposure estimation using the noise and air pollution models of the full cohort is currently ongoing. Since the inclusion of participants was independent of their place of residence, we have no reason to suspect geographical differences between participants in the first data release and the complete sample. Our study area is relatively rural compared to other parts of the Netherlands [36]. Levels of air pollution and noise exposures are lower than other parts of the Netherlands, due to for example lower population densities, and less extensive road networks. For example, exposure to $\mathrm{NO}_{2}$ in the EPIC-PROSPECT cohort located in the city of Utrecht and surrounding areas was on average $26.7 \mu \mathrm{g} / \mathrm{m}^{3}$ [37], compared to $15.7 \mu \mathrm{g} / \mathrm{m}^{3}$ in LifeLines. Conclusions based on research undertaken with LifeLines data will therefore be limited to exposure levels in that particular range. A major challenge in environmental epidemiology includes accurate exposure assessment [22, 38]. Actual measurement of individual-level exposures in a cohort as large as LifeLines would be impossible. Therefore other approaches to estimate exposures are used, such as land use regression modeling. Use of these models introduces misclassification of exposure to a varying degree; for example, due to daily mobility and longterm residential mobility [39]. In LifeLines, misclassification due to residential mobility can be tackled because data is available on address history, which is for some participants available from periods as early as year 1943. Future research should focus on characterizing exposures in earlier years, allowing for assessment of long-term exposures which is relevant for life course epidemiology. The collection of work addresses allows for outdoor exposure estimation of noise and air pollution at the work location. Combining exposures at home and work location will result in better estimation of an individual's exposure [12].

\section{Conclusions}

The combination of harmonized environmental exposures, relevant mediators and modifiers, and extensive assessment of multiple health outcomes makes LifeLines a great resource for environmental epidemiology, which it aims to be for the national and international scientific community. This paper provides an overview of the cohorts' assessments that are relevant for environmental epidemiology. Key research questions that are investigated in LifeLines are about effects of noise, air pollution, and occupational exposures on healthy ageing [40-45].

\section{Abbreviations}

BioSHaRE, Biobank Standardisation and Harmonisation for Research Excellence in the European Union; BMI, body mass index; CNOSSOS-EU, Common Noise Assessment Methods in Europe; CORINE, coordination of information on the environment; $\mathrm{dB}(\mathrm{A})$, Decibel (A); DBP, diastolic blood pressure; ECG, electrocardiogram; ESCAPE, European Study of Cohorts for Air Pollution Effects; EU-wide models, European wide models; FEV1, forced expiratory volume in $1 \mathrm{~s}$; FVC, forced vital capacity; GIS, geographic information system; HYENA study, HYpertension and Exposure to Noise near Airports study; $I Q R$, interquartile range; ISO, international Organization for Standardization; $L_{\text {day, }}$ a-weighted equivalent noise level over the 12-h day time period from 07.00 to $19.00 \mathrm{~h} ; L_{\text {den, }}$ a-weighted equivalent noise level over the day-evening-night time period of $24 \mathrm{~h}$; $\mathrm{L}_{\text {night }}$ a-weighted equivalent noise level over the 8-h night time period from 23.00 to $07.00 \mathrm{~h}$; LUR, land use regression; $\mathrm{NO}_{2}$ background, background level of nitrogen dioxide; $\mathrm{NO}_{2}$, nitrogen dioxide; $\mathrm{PM}_{10}$, particulate matter with diameter $\leq 10 \mu \mathrm{m} ; \mathrm{PM}_{2.5}$ absorbance, reflectance on $\mathrm{PM}_{2.5}$ filters, i.e. marker of black carbon; $\mathrm{PM}_{2.5}$, particulate matter with diameter $\leq 2.5 \mu \mathrm{m}$; RMSE, root mean square error; SBP, systolic blood pressure; SD, Standard deviation; SOPs, standard operating procedures; WoON questionnaire, WoonOnderzoek Nederland

\section{Acknowledgements}

The authors wish to acknowledge all participants of the LifeLines Cohort Study, the contributing research centers delivering data to LifeLines, and everybody involved in the set up and implementation of the study. The authors thank Jasper Bovenberg for providing advice on ethical and legal issues regarding environmental data.

\section{Funding}

The LifeLines Cohort Study, and generation and management of GWAS genotype data for the LifeLines Cohort Study is supported by the Netherlands Organization of Scientific Research NWO (grant 175.010.2007.006), the Economic Structure Enhancing Fund (FES) of the Dutch government, the Ministry of Economic Affairs, the Ministry of Education, Culture and Science, the Ministry for Health, Welfare and Sports, the Northern Netherlands Collaboration of Provinces (SNN), the Province of Groningen, University Medical Center Groningen, the University of Groningen, Dutch Kidney Foundation and Dutch Diabetes Research Foundation. The research leading to these results has received funding from the European Union Seventh Framework Programme (FP7/2007-2013) under grant agreement $n^{\circ} 261433$ (Biobank Standardisation and Harmonisation for Research Excellence in the European Union - BioSHaRE-EU). The funding bodies had no role in the design, collection, analysis, and interpretation of data; in the writing of the manuscript; and in the decision to submit the manuscript for publication. LifeLines (BRIF 4568) is engaged in a Bioresource Research Impact Factor (BRIF) policy pilot study, details of which can be found at https://www.bioshare.eu/content/bioresource-impact-factor.

\section{Availability of data and materials}

LifeLines adheres to standards for open data availability. The data catalogue of LifeLines is publicly accessible on www.lifelines.net. All international researchers can apply for data at the LifeLines research office (LLscience@umcg.nl). The LifeLines system allows access for reproducibility of the study results.

\section{Competing interests}

The authors declare that they have no competing interests.

\section{Author's contributions}

NS, SS, JR and RS contributed to the conception and design of the LifeLines Cohort Study. All authors were involved in acquisition of the exposure data for LifeLines. WZ performed the data analyses and drafted the manuscript. All authors critically reviewed, revised and approved the final version of the manuscript.

\section{Consent for publication}

Not applicable.

\section{Ethics approval and consent to participate}

All procedures performed in studies involving human participants were in accordance with the ethical standards of the institutional and/or national research committee and with the 1964 Helsinki declaration and its later amendments or comparable ethical standards. 


\section{Author details}

'Department of Epidemiology, University Medical Center Groningen, HPC CC72, University of Groningen, PO Box 30.0019700 RB Groningen, The Netherlands. ${ }^{2}$ Department of Epidemiology and Biostatistics, MRC-PHE Centre for Environment and Health, Imperial College London, London, UK. ${ }^{3}$ Swiss Tropical and Public Health Institute, Basel, Switzerland. ${ }^{4}$ University of Basel, Basel, Switzerland. ${ }^{5}$ LifeLines Cohort Study, Groningen, The Netherlands. ${ }^{6}$ Department of Psychiatry, University Medical Center Groningen, University of Groningen, Groningen, The Netherlands.

\section{Received: 10 March 2016 Accepted: 23 May 2016} Published online: 01 August 2016

\section{References}

1. Been JV, Nurmatov UB, Cox B, Nawrot TS, van Schayck CP, Sheikh A. Effect of smoke-free legislation on perinatal and child health: a systematic review and meta-analysis. Lancet. 2014;383:1549-60.

2. Clancy L, Goodman P, Sinclair H, Dockery DW. Effect of air-pollution control on death rates in Dublin, Ireland: an intervention study. Lancet. 2002;360: $1210-4$

3. Hamlin C, Sheard S. Revolutions in public health: 1848, and 1998? BMJ. 1998;317:587-91.

4. Pekkanen J, Pearce N. Environmental epidemiology: challenges and opportunities. Environ Health Perspect. 2001;109:1-5.

5. Doiron D, Burton P, Marcon Y, Gaye A, Wolffenbuttel BH, Perola M, et al. Data harmonization and federated analysis of population-based studies: the BioSHaRE project. Emerg Themes Epidemiol. 2013;10:12.

6. van Vliet-Ostaptchouk JV, Nuotio ML, Slagter SN, Doiron D, Fischer K, Foco $L$, et al. The prevalence of metabolic syndrome and metabolically healthy obesity in Europe: a collaborative analysis of ten large cohort studies. BMC Endocr Disord. 2014;14:9.

7. Stolk RP, Rosmalen JGM, Postma DS, de Boer RA, Navis G, Slaets JPJ, et al. Universal risk factors for multifactorial diseases: LifeLines: a three-generation population-based study. Eur J Epidemiol. 2008;23:67-74.

8. Scholtens S, Smidt N, Swertz MA, Bakker SJ, Dotinga A, Vonk JM, et al. Cohort Profile: LifeLines, a three-generation cohort study and biobank. Int. J. Epidemiol. 2014;doi: 10.1093/ije/dyu229.

9. Klijs B, Scholtens S, Mandemakers JJ, Snieder H, Stolk RP, Smidt N. Representativeness of the LifeLines Cohort Study. PLoS One. 2015;10: e0137203.

10. Fuks KB, Weinmayr G, Foraster M, Dratva J, Hampel R, Houthuijs D, et al. Arterial blood pressure and long-term exposure to traffic-related air pollution: an analysis in the European Study of Cohorts for Air Pollution Effects (ESCAPE). Environ Health Perspect. 2014;122:896-905.

11. Fischer PH, Marra M, Ameling CB, Hoek G, Beelen R, de Hoogh K, et al. Air pollution and mortality in seven million adults: the Dutch environmental longitudinal study (DUELS). Environ Health Perspect. 2015;123:697-704.

12. Ragettli MS, Phuleria HC, Tsai M-Y, Schindler C, de Nazelle A, Ducret-Stich $\mathrm{RE}$, et al. The relevance of commuter and work/school exposure in an epidemiological study on traffic-related air pollution. J Expo Sci Environ Epidemiol. 2015;25:474-81.

13. Götschi T, Heinrich J, Sunyer J, Künzli N. Long-term effects of ambient air pollution on lung function: a review. Epidemiology. 2008;19:690-701.

14. Newby DE, Mannucci PM, Tell GS, Baccarelli AA, Brook RD, Donaldson K, et al. Expert position paper on air pollution and cardiovascular disease. Eur Heart J. 2014:36:83-93b.

15. Beelen R, Hoek G, Vienneau D, Eeftens M, Dimakopoulou K, Pedeli X, et al. Development of NO2 and NOx land use regression models for estimating air pollution exposure in 36 study areas in Europe - The ESCAPE project. Atmos Environ. 2013;72:10-23.

16. Eeftens M, Beelen R, de Hoogh K, Bellander T, Cesaroni G, Cirach M, et al. Development of Land Use Regression models for PM(2.5), PM(2.5) absorbance, PM(10) and PM(coarse) in 20 European study areas; results of the ESCAPE project. Environ Sci Technol. 2012:46:11195-205.

17. Vienneau D, de Hoogh K, Bechle MJ, Beelen R, van Donkelaar A, Martin RV et al. Western European land use regression incorporating satellite- and ground-based measurements of NO2 and PM10. Environ Sci Technol. 2013; 47:13555-64.

18. Basner M, Babisch W, Davis A, Brink M, Clark C, Janssen S, et al. Auditory and non-auditory effects of noise on health. Lancet. 2013;383:1325-32.
19. Kephalopoulos S, Paviotti M, Anfosso-Lédée F, Van Maercke D, Shilton S, Jones $\mathrm{N}$. Advances in the development of common noise assessment methods in Europe: The CNOSSOS-EU framework for strategic environmental noise mapping. Sci Total Environ. 2014:482-483:400-10.

20. Morley DW, de Hoogh K, Fecht D, Fabbri F, Bell M, Goodman PS, et al. International scale implementation of the CNOSSOS-EU road traffic noise prediction model for epidemiological studies. Environ Pollut. 2015;206:332-41.

21. European Environment Agency. Corine Land Cover 2000 Seamless Vector Data (V16) [Internet]. 2015 [cited 2015 Jul 1]. Available from: http://www.eea.europa. eu/data-and-maps/data/corine-land-cover-2000-clc2000-seamless-vectordatabase-4.

22. Rothman KJ. Methodologic frontiers in environmental epidemiology. Environ Health Perspect. 1993;101 Suppl 4:19-21.

23. Baliatsas C, Bolte J, Yzermans J, Kelfkens G, Hooiveld M, Lebret E, et al. Actual and perceived exposure to electromagnetic fields and non-specific physical symptoms: An epidemiological study based on self-reported data and electronic medical records. Int J Hyg Environ Health. 2015;218:331-44.

24. International Organization for Standardization (ISO). Acoustics - Assessment of Noise Annoyance by Means of Social and Socio-acoustic Surveys; ISO/TS 15666. Geneva; 2003.

25. Babisch W, Houthuijs D, Pershagen G, Cadum E, Katsouyanni K, Velonakis M, et al. Annoyance due to aircraft noise has increased over the years-results of the HYENA study. Environ Int. 2009;35:1169-76.

26. Porsius JT, Claassen L, Smid T, Woudenberg F, Timmermans DRM. Health responses to a new high-voltage power line route: design of a quasiexperimental prospective field study in the Netherlands. BMC Public Health. 2014:14:237.

27. Sudlow C, Gallacher J, Allen N, Beral V, Burton P, Danesh J, et al. UK biobank: an open access resource for identifying the causes of a wide range of complex diseases of middle and Old Age. PLoS Med. 2015:12:e1001779.

28. Janson C, Chinn S, Jarvis D, Zock J-P, Torén K, Burney P. Effect of passive smoking on respiratory symptoms, bronchial responsiveness, lung function, and total serum lgE in the European Community Respiratory Health Survey: a cross-sectional study. Lancet. 2001;358:2103-9.

29. GGD Groningen. Gezondheidsenquete [Internet]. 2015. [cited 2015 Sep 1]. Available from: http://ggd.groningen.nl/onderzoek/gezondheidsprofiel

30. Rijksoverheid. WoonOnderzoek Nederland (WoON) [Internet]. 2015. [cited 2015 Sep 1]. Available from: https://www.rijksoverheid.nl/onderwerpen/ onderzoeken-over-bouwen-wonen-en-leefomgeving/inhoud/lopendeonderzoeken/woononderzoek-nederland-woon

31. Leal C, Chaix B. The influence of geographic life environments on cardiometabolic risk factors: a systematic review, a methodological assessment and a research agenda. Obes Rev. 2011;12:217-30.

32. Moser A, Panczak R, Zwahlen M, Clough-Gorr KM, Spoerri A, Stuck AE, et al. What does your neighbourhood say about you? A study of life expectancy in 1.3 million Swiss neighbourhoods. J Epidemiol Community Health. 2014; 68:1125-32.

33. Statistics Netherlands. CBS - Kerncijfers wijken en buurten 2004-2013 [Internet]. Cent. Bur. voor Stat. Den Haag/Heerlen. 2013. Available from: https://www.cbs.nl/nl-nl/maatwerk/2015/36/kerncijfers-wijken-en-buurten2013

34. Tigchelaar EF, Zhernakova A, Dekens JAM, Hermes G, Baranska A, Mujagic Z, et al. Cohort profile: LifeLines DEEP, a prospective, general population cohort study in the northern Netherlands: study design and baseline characteristics. BMJ Open. 2015;5, e006772

35. Schwartz J, Bellinger D, Glass T. Exploring potential sources of differential vulnerability and susceptibility in risk from environmental hazards to expand the scope of risk assessment. Am J Public Health. 2011;101 Suppl 1:S94-101.

36. Maas J, Verheij RA, de Vries S, Spreeuwenberg P, Schellevis FG, Groenewegen PP. Morbidity is related to a green living environment. J Epidemiol Community Health. 2009;63:967-73.

37. Beelen R, Raaschou-Nielsen O, Stafoggia M, Andersen ZJ, Weinmayr G, Hoffmann B, et al. Effects of long-term exposure to air pollution on naturalcause mortality: an analysis of 22 European cohorts within the multicentre ESCAPE project. Lancet. 2014;383:785-95.

38. Peters A, Hoek G, Katsouyanni K. Understanding the link between environmental exposures and health: does the exposome promise too much? J Epidemiol Community Health. 2012;66:103-5.

39. Chang ET, Adami H-O, Bailey WH, Boffetta P, Krieger Rl, Moolgavkar SH, et al. Validity of geographically modeled environmental exposure estimates. Crit Rev Toxicol. 2014;44:450-66. 
40. Zijlema WL, Wolf K, Emeny R, Ladwig KH, Peters A, Kongsgård H, et al. The association of air pollution and depressed mood in 70,928 individuals from four European cohorts. Int J Hyg Environ Health. 2016;219:212-9.

41. Zijlema WL, Morley DW, Stolk RP, Rosmalen JGM. Noise and somatic symptoms: a role for personality traits? Int J Hyg Environ Health. 2015;218:543-9.

42. Zijlema WL, Klijs B, Stolk RP, Rosmalen JGM. (Un)healthy in the city: respiratory, cardiometabolic and mental health associated with urbanity. PLoS One. 2015; 10:e0143910.

43. de Jong K, Boezen HM, Kromhout H, Vermeulen R, Vonk JM, Postma DS, et al. Occupational exposure to vapors, gases, dusts, and fumes is associated with small airways obstruction. Am J Respir Crit Care Med. 2014;189:487-90.

44. de Jong K, Vonk JM, Timens W, Bossé Y, Sin DD, Hao K, et al. Genome-wide interaction study of gene-by-occupational exposure and effects on FEV1 levels. J Allergy Clin Immunol. 2015;136:1664-72:e1-14.

45. de Jong K, Boezen HM, Kromhout H, Vermeulen R, Postma DS, Vonk JM, et al. Pesticides and other occupational exposures are associated with airway obstruction: the LifeLines cohort study. Occup Environ Med. 2014;71:88-96.

\section{Submit your next manuscript to BioMed Central} and we will help you at every step:

- We accept pre-submission inquiries

- Our selector tool helps you to find the most relevant journal

- We provide round the clock customer support

- Convenient online submission

- Thorough peer review

- Inclusion in PubMed and all major indexing services

- Maximum visibility for your research

Submit your manuscript at www.biomedcentral.com/submit 